\title{
"El lugar en donde abundan los venados". Historia, narraciones y memorias locales del municipio de Comasagua, El Salvador ${ }^{1}$
}

\author{
"The place where deer abound." History, stories and local memories \\ of the municipality of Comasagua, El Salvador
}

José Heriberto Erquicia-Cruz²

Director del Museo Nacional de Antropología "David J. Guzmán"

jose.erquicia@utec.edu.sv

Martha Marielba Herrera ${ }^{3}$

Investigadora

marielba@gmail.com

Recibido: 28/01/2015 - Aceptado: 13/06/2015

\section{Resumen}

Comasagua es rica en historia y tradición. La enseñanza de la historia en el sistema educativo salvadoreño tiene grandes vacíos, uno de tantos es no tomar en cuenta las narraciones y memorias locales, dedicándose solamente a examinar una historia nacional, excluyendo a las comunidades que se encuentran al margen de la sociedad salvadoreña dominante. A través de un método historiográfico y de técnicas de entrevistas semi estructuradas y grupos focales se llegó a conocer una parte de la historia de las comunidades. Desde la época prehispánica hasta el siglo XXI, los comasagüenses han resguardado, mediante la oralidad y la memoria, su

\section{Abstract}

Comasagua is rich in history and tradition. The teaching of history in the Salvadoran educational system has big gaps; one of many is not accounting for narratives and local memories thus only considering a national history which excludes those communities that lie outside the members of the dominant Salvadoran society. Part of the history of these communities was found by means of the application of the historical method and the use of techniques such as semi-structured interviews and focus groups. From the pre-Hispanic times up to the XXI century, the people from Comasagua have safeguarded their history through their memories and oral history.

Este artículo se deriva de la investigación "Historias, patrimonios e identidades en el municipio de Comasagua, La Libertad, El Salvador".

Director del Museo Nacional de Antropología "David J. Guzmán", docente e investigador de la Utec. Correo electrónico jose.herquicia@utec.edu.sv.

Licenciada en Antropología, co-investigadora en la Universidad Tecnológica de El Salvador. Correo electrónico marielba@gmail.com 
historia. Estos aportes permiten determinar cómo, en el país, varios colectivos siguen vigentes, revelando su diversidad étnica, su cosmovisión y sus saberes.

\section{Palabras clave}

Historia, oralidad, identidades étnicas, Comasagua.
These contributions help determine how several groups in the country are still current, hence revealing their ethnic diversity, their worldview and their knowledge.

\section{Keywords}

History, oral history, ethnic identities, Comasagua.

\section{Introducción}

En El Salvador del siglo XXI existe un interés, desde las localidades, por conocer sus orígenes, sus historias, sus patrimonios y otros de los elementos que conforman sus identidades. La localidad de Comasagua, ubicada al suroeste de San Salvador, es junto con otros municipios de la zona de la cordillera del Bálsamo, que comparte una población de ascendencia indígena de habla nahua-pipil.

Los elementos patrimoniales de la cultura material y las manifestaciones de la cultura viva de sus habitantes son componentes esenciales en la construcción de la historia de las poblaciones de El Salvador. La enseñanza de la historia en el sistema educativo salvadoreño contiene vacíos. Uno de ellos es el referido a las historias locales, pues la historia se dedica a examinar una historia nacional y urbana con muchos sesgos, suprimiendo a las comunidades que se encuentran al margen de la sociedad salvadoreña dominante.

Las comunidades de Comasagua, aunque se localicen muy cercanas a la ciudad de Santa Tecla, se han encontrado al margen de la dinámica social urbana. Es por ello que revelar las diversas prácticas culturales que se desarrollan entre las comunidades de los cantones que componen el municipio, a partir de la viva voz de los actores sociales, como agentes de cambio, era unas de las razones vitales de la propuesta de esta investigación. En cada una de las comunidades de El Salvador concurre una demanda por conocer y apreciar su historia, de la que numerosas veces poseen imágenes fraccionadas. Un pueblo que comprende, valora y se apropia de la historia de su comunidad se convierte en un colectivo que emprende de mejor manera las vicisitudes a que se enfrenta a diario.
Dicha investigación se realizó en asocio, a través de un convenio específico de cooperación entre la Universidad Tecnológica de El Salvador, Utec, y la Asociación Comunitaria Unida por el Agua y la Agricultura, Acua, instituciones interesadas en constituir vínculos, por el reconocimiento e importancia de promover el rescate cultural de la cordillera del Bálsamo, en la cual se ubica Comasagua.

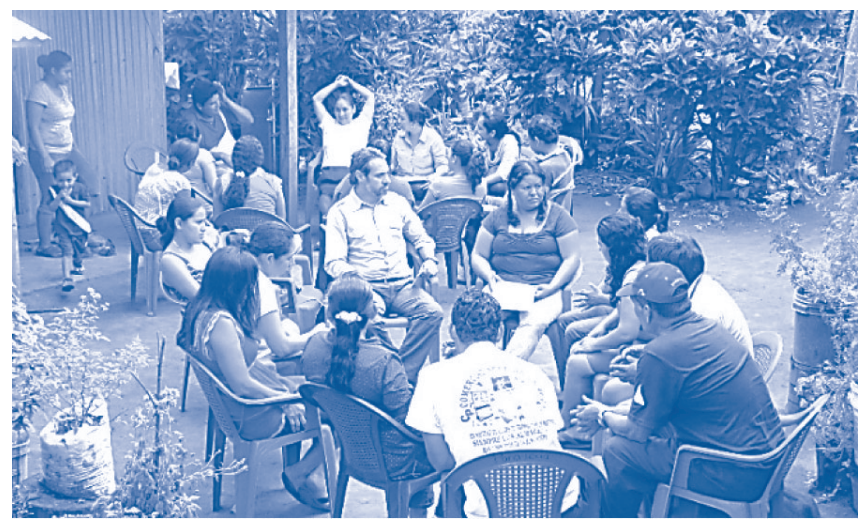

Figura 1.

Vista de la ejecución de dos grupos focales en la comunidad La Dalia, municipio de Comasagua. Fotografía propia.

\section{Metodología}

En el abordaje metodológico de la presente investigación se utilizó el método etnográfico, ${ }^{2}$ que permitió conocer la información de primera mano de los pobladores del municipio de Comasagua, tanto en el área urbana como en la rural, a partir de la técnica de grupos focales. Las entrevistas logradas mediante la estrategia tenían el propósito de registrar cómo los participantes elaboran grupalmente su realidad y experiencia. Esta técnica está suscrita con la idea de grupos

El método etnográfico alude al proceso metodológico global que caracteriza a la antropología social y que es utilizado, en términos generales, por las Ciencias Sociales. 
de discusión organizados alrededor de una temática, dentro de la cual se delimitan metodológicamente el objeto y los objetivos de los grupos focales en la contribución que hacen al conocimiento de lo social (Aigneren, 2002). Dentro de esta recolección etnográfica también se hizo uso del registro visual, a través de herramientas como la cámara fotográfica, que permitieron documentar las entrevistas realizadas y varias actividades llevadas a cabo en las comunidades del municipio de Comasagua.

Asimismo, se llevaron a cabo entrevistas semiestructuradas focalizadas y realizadas en un entorno de confianza en el que los entrevistados alcanzaran a profundizar con sus respuestas a las preguntas que se les plantearon; todo ello con miras a obtener más información. Por medio de esta técnica, se construyó un instrumento donde se abordaron los tópicos de interés en la búsqueda de respuestas del problema de investigación (Vela Peón, 2001).

Se manejó también el método historiográfico heurístico con la búsqueda y recopilación de fuentes documentales primarias y secundarias, para luego realizar el análisis y la crítica de dichas fuentes. De igual manera, se recurrió al método hermenéutico, como parte importante de la lectura, comprensión e interpretación de las fuentes obtenidas, a partir de su búsqueda y recopilación. Teniendo en cuenta la complejidad que debe tener un trabajo acerca de historia e identidad local, se delimitó el desarrollo de resultados desde los ejes de historia, medicina tradicional, identidad indígena y saberes tradicionales, desarrollando así algunas de las herramientas teóricas que permitieron analizar este contexto sociocultural.

En el estudio se realizó un total de tres entrevistas a informantes de Comasagua, tanto en el área urbana como en la rural. Asimismo, se realizaron doce grupos focales; uno urbano y los demás rurales. En las comunidades Los Cortés, San Chico, Violeta Arcoíris, La Dalia, San Antonio, San José Guadalupe, casco urbano y dos en cada una de las comunidades El Sitio y El Peñón.

\section{Resultados}

\section{Cultura y prácticas: medicina tradicional en Comasagua}

Los diferentes grupos sociales tienen sus propias formas de concebir a la salud-enfermedad-curación, sobre todo si tienen poco acceso a la salud. Eso implica que desarrollan sus propias prácticas de medicina tradicional. Por ello es importante tomar en cuenta su cultura y tradición, pues son estas las que hasta cierto punto definen cómo las personas de una comunidad van a hacerle frente a las enfermedades que las afectan. Al tener el municipio de Comasagua un pasado prehispánico en el que la medicina tradicional se fusionó con conocimientos y prácticas traídos con la conquista europea, se puede comprender cómo en la actualidad estos saberes y enfermedades deben ser llevados más allá del cuerpo.

Las enfermedades y las prácticas terapéuticas que aplican actualmente las comunidades han sido heredadas de sus antepasados. Según Castillo (2012), la medicina "tradicional permite la sobrevivencia a un sistema de salud limitado proporcionado por parte del gobierno" (Castillo, 2012, p. 34). Para el caso de Comasagua, que no es el único municipio en el país que realiza dichas prácticas, poco a poco están desapareciendo. Estos saberes de medicina tradicional, que tienen por finalidad sanar de enfermedades no solo físicas, sino también espirituales y psicológicas, eran llevados a cabo por personas de la comunidad que tenían ese conocimiento, es decir, curanderos y parteras. Sin embargo, también hay muchos casos en los que son las personas mismas las que, con el conocimiento que tienen de las plantas medicinales, hacen sus propias recetas y se autocuran. Esto evidencia que en el actual municipio de Comasagua estos saberes se han mantenido en el tiempo, pero que ya no existe como tal el personaje del curandero o de la partera. 


\section{La necesidad de tener salud: una mirada al pasado}

Desde la antropología social se ha dejado establecido que la medicina es un producto cultural del grupo humano, por lo que se debe investigar desde el contexto en el que ocurre (Ghidinelli, 1984), por esta razón se debe conocer y comprender hasta donde se pueda el historial de enfermedades que ha afectado a la población desde finales del siglo XIX. Para este caso, enfocándose en los nacimientos y muertes de la población comasagüense debido a las pobres condiciones de vida y casi nulo acceso a la salud con el que contaban. Sobre todo, los pobladores indígenas eran los más afectados con las pestes y enfermedades como viruela, fiebre amarilla, tos ferina, fiebres, catarro y alguna que otra enfermedad sobrenatural registrada en documentos civiles del siglo XX.

Generalmente, los relatos orales hacen alusión a epidemias o enfermedades que diezmaron a la población. En este caso, en la primera mitad del siglo XX la mortandad infantil por sarampión se hace evidente en los registros consultados. En Comasagua aún se mantienen anécdotas alusivas a la viruela y al sarampión, en las que se han fusionado ambos padecimientos. Una de las entrevistadas comentó que esta aparición

ocurrió más o menos en el año 1950. Aparecieron dos niños agarraditos de la mano, eran el varón y la hembra; esos eran los espíritus de esas enfermedades. Uno representaba la enfermedad del sarampión y el otro el de la varicela.

En el caso del sarampión, los entrevistados comentaron cómo, en años anteriores, empleaban plantas para curar a los enfermos. Lo expresaban así:

Les daba, y cuando les salía en la garganta se morían ahogados. Por eso, cuando a un niño le sale, tal vez varicela $u$ otra cosa que le da a los niños, uno los pone a mascar un ajo y se lo soba en los oídos, las narices... hasta que le llegue aquí a la "gargantilla", y le llegue a la boca, y se le sopla con ajo la nariz y los ojos.

\section{"Usamos plantas que curan..."}

Durante los períodos de pestes, si bien existieron jornadas de vacunación y códigos sanitarios para evitar una epidemia mayor, las áreas rurales enfrentaron esas situaciones con medicina tradicional; con plantas que tenían a su alcance para curar las enfermedades que las aquejaban. El conocimiento debía provenir de personas que lo tuvieran, ya fueran los abuelos o curanderos de la localidad que les permitieran buscar una salida natural para restablecer la salud.

Los mismos comasagüenses mencionan que "al no tener farmacias ni hospitales cerca, es por medio de remedios que se curan, además, el alcalde manda carros y kits (botiquines) para que los Ileven al hospital". Muchos son los conocimientos sobre remedios caseros que se recopilaron en Comasagua acerca del uso de plantas medicinales que tienen a su alcance. Según expusieron los entrevistados, lo aprendieron de sus abuelos o padres, pero reconocen que hay enfermedades físicas que no pueden ser tratadas con plantas, sino que deben ser atendidas por médicos en clínicas u hospitales. Ellos se refieren a enfermedades como tos, gripe y dolor de estómago, entre otras. También se debe tomar en cuenta que hay enfermedades asociadas a lo sobrenatural como el mal del ojo, el susto o espanto, el mal de aire, molestias causadas por malos y daños ocasionados por brujería, es decir, aquellas que afectan al espíritu de las personas y que urgen de una ayuda para sanarlos.

Este personaje importante comparte con el paciente el mismo contexto cultural y simbólico que permite que se establezca una solución más eficaz para la sanación. Es decir, el paciente debe confiar y creer en su médico tradicional para que la cura llegue pronto; para ello deberá tomar al pie de la letra el tratamiento que se le dé. La medicina ofrecida debe ser una mezcla de productos naturales orgánicos e inorgánicos y algunos artificiales, en forma de remedios populares que deben ser transformados y manipulados. Para los comasagüenses, se trata de una herencia cultural antigua. Lo explicaron así:

Alguien le enseñó a alguien; y alguien le enseño a alguien. Vaya, nosotros. Yo tengo 35 años. Desde que yo existo y tengo conocimiento de las cosas, 
por ejemplo, mi mamá a veces agarra ceniza en hojas de huerta para el dolor de estómago; lo ponían así, y ya se te va a quitar. Entonces, en alguna medida, alguien más antes que ella lo hizo y funcionó. Entonces eso ha venido haciendo.

Una de las enfermedades más comunes que afectan a la población es la tos. La cura está a su alcance. Según ellos, se cosen "hojas de eucalipto, hojas de mango indio, una cebolla moradita tiernita, este..., candela de izote. También le ponen zacate limón y cojollitos de veranera. También se usa manzanilla, jengibre y miel de abeja". Cada uno de los ingredientes los encuentra en su entorno natural.

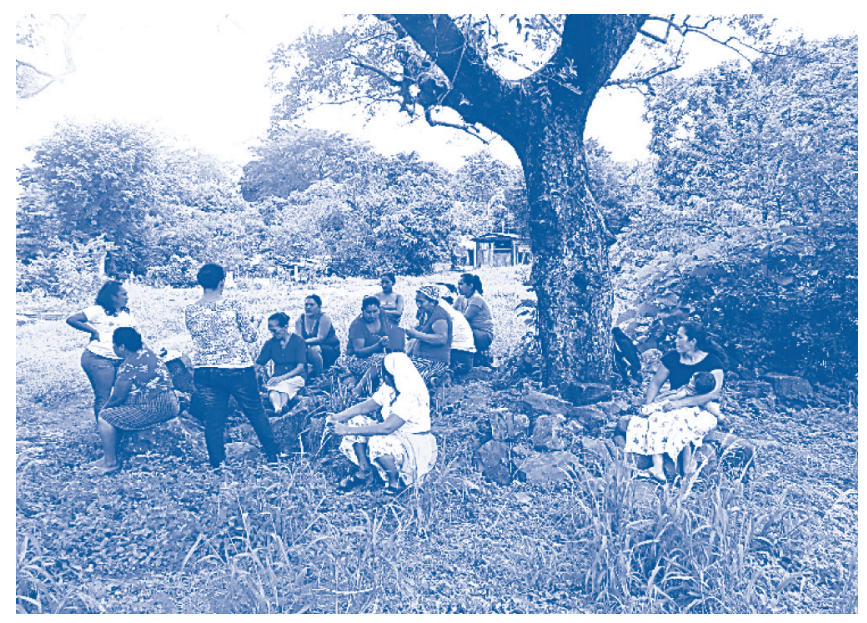

Figura 2.

Vista de la realización del grupo focal de mujeres del cantón El Sitio, municipio de Comasagua. Fotografía propia.

\section{Sabiduría ancestral: la labor de las parteras o comadronas}

Una tradición muy importante, que tiene un origen prehispánico y que fue poco a poco tomando elementos del cristianismo, es la del cuido de las mujeres durante el embarazo, a la hora del parto y de los cuidados posparto de ella y su hijo. En el ámbito rural, la comadrona se volvió indispensable en ese momento importante. Acudir a ella garantizaba el éxito del embarazo y del nacimiento del niño. Este personaje atiende a una embarazada durante el parto, utilizando conocimientos y prácticas adquiridos tradicionalmente. Es la primera persona que recibe a los nuevos ciudadanos, definiendo si es niña o niño; luego los presenta a la familia (Velásquez, 1996).

A inicios del siglo $\mathrm{XX}$, la labor de las parteras era reconocida por el servicio social que proveían dentro de las comunidades rurales. A ese contexto de pobreza y casi nulo acceso a hospitales o clínicas de salud se debe que muchos infantes hayan nacido con asistencia de una persona que adquirió sus conocimientos de partería por sí misma o por aprendizaje con otras parteras tradicionales.

Las mujeres comasagüenses entrevistadas aportaron, con sus relatos, a la comprensión de cómo las parteras les ayudaban a prepararse para tener un parto sin dificultades. Una de las entrevistadas comentó lo siguiente:

Me dijo que no me pusiera guacales aquí porque se pandeaban los niños, estando embarazada. Y que no me pasara cercos porque se maneaban, o que no me pasara así mangueras que estaban tiradas en el suelo; que no pasara sobre ellas porque el cordón umbilical se les maneaba en la cabecita.

Muchos saberes ancestrales en los pueblos originarios se están perdiendo, tal como lo afirma la "Política municipal para la igualdad de género del municipio de Nahuizalco, departamento de Sonsonate (2009-2010)" (Quintanilla, 2010). En ella dice que en las tradiciones orales también se han perdido creencias; la medicina natural con la cual se curaban, conocimiento transmitido por las mujeres, especialmente por las parteras. En el apartado sobre los derechos de las mujeres indígenas, menciona que

\section{se reconoce expresamente a las mujeres indígenas parteras, estableciendo que tienen derecho a ejercer su oficio y a que se respeten sus costumbres del oficio de parteras en cuanto al uso de medicinas y procedimientos y demás elementos culturales propios de su ejercicio (D.O., 2012, p. 61).}

\section{Religiosidad y creencias: ciclo agrícola-festivo en San Matheo Comasahua}

El pensamiento religioso y su acción permiten generar o reforzar el sentido de pertenencia y colectividad en grupos 
sociales, además de lazos de amistad y parentesco que se generan a partir de una experiencia colectiva. Esta idea de compartir las festividades en el municipio de Comasagua es importante, pues con el tiempo otros grupos religiosos han ido incrementándose. Para el caso, las festividades religiosas católicas son un referente importante de tradiciones y creencias que se han mantenido con el tiempo. Actualmente, en este municipio, ya no se realizan celebraciones grandes en honor a su patrono san Mateo, pues hay un conflicto entre la comunidad y el párroco de la iglesia. Sin embargo, en los cantones del municipio es donde se pueden evidenciar estas festividades.

Dentro del mundo campesino, las ritualidades están orientadas en muchos casos a la agricultura. En este contexto, se ha fusionado el cristianismo con elementos del mundo mesoamericano de celebraciones y cultos al agua, la tierra, la fertilidad y la abundancia, todos ellos a partir del mundo agrícola, en el que se desarrollan y conviven a diario; en ese espacio donde la tierra, el agua, la lluvia y la milpa juegan un papel determinante en su cultura campesina, que tuvo un origen en la cultura pipil (Erquicia, Herrera y Pleitez, 2014, p. 59). Este remanente religioso y cultural se mantiene vigente, tanto en el caso urbano de Comasagua como en sus cantones.

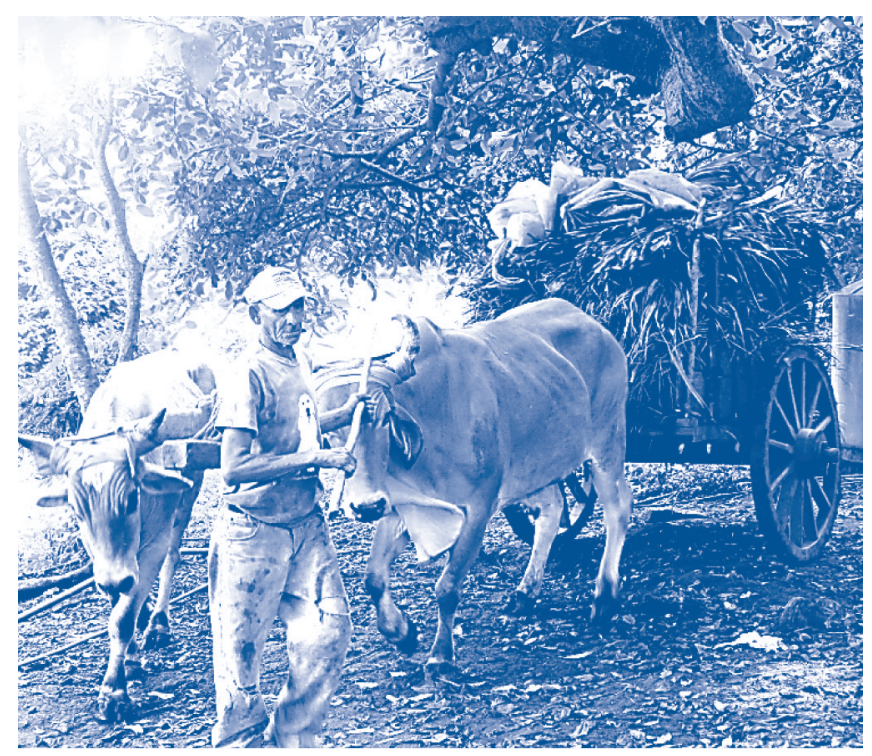

Figura 3.

Vista de un campesino arriando su yunta de bueyes en la comunidad Los Cortes, municipio de Comasagua. Fotografía propia.
Son tres las fiestas que, según los informantes, se realizan "a beneficio de cualquier santo que ellos quieran celebrar". Estas son: a san Mateo, el Día de la Cruz y al Señor de Esquipulas. Si se adapta el ciclo agrícola con los rituales y las estaciones climáticas, se comprende que entre los meses de diciembre y enero se inicia la preparación de la tierra, así como la bendición de la semilla (15 enero, Señor de Esquipulas). Luego, el 3 de mayo (Día de la Cruz), se pide por la lluvia y la fertilidad de la tierra. La fiesta del maíz es muy importante para los agricultores, pues en comunidad se comparten los frutos recolectados durante la siembra. Luego, con la festividad de san Mateo, en el mes de septiembre, se marca el final de las lluvias. Con el transcurrir del tiempo, cada una de las festividades se han adaptado a los cambios climáticos, sociales y culturales que han modificado elementos sagrados o rituales, pero que para las comunidades tienen un sentido propio que valida la tradición y las creencias. Las fiestas religiosas por cantones y caseríos, en Comasagua, se realizan de enero a diciembre.

\section{Identidades indígenas en Comasagua}

A finales del siglo XIX, en El Salvador las comunidades indígenas fueron violentamente excluidas y marginadas del proceso de formación del Estado-Nación liberal. Se les arrebataron las tierras comunales y ejidales, convirtiendo en mano de obra asalariada a miles de ellos, que se resistían a enajenar su fuerza de trabajo (Marroquín: 1975, p. 766). Durante mucho tiempo el Estado salvadoreño ha pretendido construir una identidad cultural hegemónica y elevarla a un status de "identidad nacional". Más allá de ello, las localidades construyen sus imaginarios identitarios a través de diferentes dinámicas y referentes, y no solo a través de la imagen hegemónica que el Estado ha planteado.

Es importante entender cómo las localidades de El Salvador van construyendo identidad, e identidades culturales, a partir de la memoria colectiva; de sus referentes históricos, simbólicos y culturales en la elaboración de su propia identidad cultural. Pero también es transcendental entender la identidad desde una perspectiva relacional. Es decir, desde un complejo proceso en que la identidad de un grupo se construye en contraposición con el otro o con los otros; y a través de la manera en que estos ven y califican al primero. Esta observación es importante en la medida en 
que los contenidos culturales de un grupo pueden cambiar o transformarse a lo largo del tiempo (el idioma indígena, el vestuario tradicional). Sin embargo, la identidad del grupo (el ser comasagüense, en este caso) puede permanecer.

En este sentido, la identidad no se construye únicamente a través de rasgos culturales perceptibles a simple vista, sino también por medio de la memoria del colectivo, la cual brinda un sentido a las anécdotas locales que trasmiten los sujetos. Es por ello que la cultura de los pueblos indígenas en la actualidad se puede apreciar desde las historias, la narrativa oral; las experiencias compartidas, las formas propias de organización social; el conocimiento local sobre el entorno físico (paisaje y territorio), aspectos de su cosmovisión; los saberes o conocimientos ancestrales que se expresan en la educación indígena, la vida, la salud y la tierra, que también forman parte de su identidad.

\section{La Comasagua indígena}

El último censo poblacional llevado a cabo en El Salvador se realizó en 2007; en él se incluiría la categoría de "raza y grupo étnico", luego de no utilizarla desde el Censo de Población de 1930. Aunque con muchas críticas por parte de las organizaciones indígenas y de defensa de los derechos humanos, por el mal manejo metodológico de la boleta censal en dicho apartado, se documentó el número de habitantes por grupo étnico. Así, aparecerían los adscritos a las comunidades lenca, kakawira, nahua-pipil y otra.

Comasagua, con un total de población de 11.870 habitantes, hombres y mujeres, para 2007, registraba un $0,05 \%$ de población adscrita como indígena de la comunidad o etnia pipil de habla náhuat (Digestyc, 2008, p. 279). Ello significaba que siete personas se declararon indígenas. Un estudio de hace más de 10 años, el cual recoge el perfil de los pueblos indígenas de El Salvador, menciona los municipios de la zona central de El Salvador que cuentan con comunidades con presencia indígena, muchos de ellos vecinos y hasta colindantes con el municipio de Comasagua, tales como, Jicalapa, Chiltiupán, Huizúcar, Jayaque, Teotepeque, Tepecoyo y Talnique, sin mencionar la población objeto de estudio en esta investigación.
Un factor importante de todas estas características o rasgos distintivos del perfil del ser indígena en El Salvador es la autodeterminación a la pertenencia a un designado pueblo indígena, pues sin ello el reconocimiento no sería complementario. Partiendo de las características adscritas al perfil del indígena salvadoreño; de las teorías sobre la etnicidad y el método etnográfico de la entrevista y los grupos focales, se reconocen las voces, las historias orales, la memoria colectiva y las percepciones, a través de la consulta sobre si hay indígenas en Comasagua, cómo piensan, viven, visten y calzan.

En la comunidad La Dalia, una mujer entrevistada originaria de la comunidad La China, al consultarle sobre la presencia de indígenas en dicha comunidad afirmaba lo siguiente:

Aquí no, pero dicen que en otras partes sí hay. Por aquí, por el lado de Guadalupe, dicen de una zona que le dicen La Herrada que está bien cabal la herradura de un caballo que los indios hicieron. La Herradura le dicen alli; que los indios antes formaron la herradura de un caballo; le dicen allí la zona de La Herradura.

Este relato se refiere a los vestigios arqueológicos del sitio conocido como Piedra Herrada, documentado en la década de 1960 por el Museo Nacional del El Salvador "David J. Guzmán", y en el que, a finales del siglo XX, se realizó una investigación de registro fotográfico y calco de los petrograbados (Escamilla, 2007, p. 12-23).

Claramente el discurso de descripción asume una posición de negación de la presencia de personas indígenas en el presente de Comasagua. Sin embargo, el tema indígena lo traslada al pasado prehispánico, a los vestigios arqueológicos, pero luego ese pasado lo vincula con las familias del presente, cuando afirma: "Piedra Herrada, que es como una divisa de los indígenas, de nuestra gente de antes, de nuestros familiares y que defendemos...". Este pensamiento sería recurrente en las entrevistas en Comasagua; de igual manera aparece en los discursos de las personas de varias comunidades investigadas, como Huizúcar, Chalchuapa, Ereguayquín, Izalco y San Alejo, cuando lo indígena queda 
relegado al pasado y no sobrevive hasta el presente, todo ello como parte del discurso creado por las instituciones del Estado salvadoreño a través de muchos años.

Otro de los referentes que aparecen frecuentemente sobre la comunidad indígena en Comasagua es a partir de la forma de vestir. Una mujer joven relataba lo siguiente:

Mi abuela me contaba, cuando estaba yo con ella, que la gente se vestía humildemente, usaban solamente ropa de tela de manta, vestidos de manta y usaban trencitas; la mayoría de las mujeres andaba con trenzas y caitiyos, zapatos de caite. Igual [ropa] de manta usaban los hombres y caites; y usaban sombrero.

En este mismo tema, una señora anciana se expresaba así:

Los indios de antes era refajos lo que se ponían; o una cosa bordada con forma de esas chapinas; hacían los refajos y se los amarraban. Y los niños, decía mi abuela, que atrás los cargaban, trabajando; y con los niños, aquí se los ponían, con una cosa, y así andaban trabajando.

Un joven, refiriéndose a una de las características de "Io indígena", como la lengua, comentaba lo siguiente:

En mi familia había gente así... Mis abuelitos hablaban, medio me recuerdo que hablaban. Incluso el lenguaje que tenemos ahora es bien diferente al que ellos tenían... Mis bisabuelos eran de Cojutepeque, de la sangre pipil. o sea que de esa gente todavía hay; no han venido unos aquí, pero todavía hay bastante gente que tiene sus palabras que no son igual a lenguaje de nosotros. Mire, hay unos ancianitos por aquí, no le puedo decir [dónde], pero sí hablan bien distinto.

Por otra parte, a la pregunta ¿qué es ser indio o qué es ser indígena?, algunos de los entrevistados, como un hombre joven, decía:

Para mí, es ser una persona original. o sea, que conserva sus raíces, o la forma de pensamiento de los indios o de los nativos, pues no tienen nada que ver con el sistema que hoy tenemos, sino que ellos basaban todo en los elementos de la tierra. Entonces, en ese sentido, digo que es ser original, o sea, ellos lo relacionaban al ser humano con los elementos de la tierra, la naturaleza; y había un equilibrio.

En este relato se está asociando lo indígena con los elementos de la visión del mundo o cosmovisión indígena y la relación con la tierra que cultivan y les provee de los elementos dadores de vida.

Un aporte interesante que surgió en las entrevistas y que está asociado al conocimiento indígena y a su cosmovisión es el origen de las enfermedades, su tratamiento y su curación, y, por supuesto, la medicina tradicional, de la cual apareció abundante información en esta investigación, a la que se le dedica un capítulo entero; sin embargo, es importante mencionar algunos casos que están más relacionados con este capítulo de la etnicidad indígena de Comasagua.

\section{Conclusiones}

La localidad de Comasagua es rica en historia y tradición. A través del tiempo, desde la época prehispánica hasta el siglo XXI, los comasagüenses han resguardado, a través de la oralidad, su historia.

Las festividades religiosas en Comasagua, según sus pobladores, no están del todo asociadas al ciclo agrícola; sin embargo, las fiestas como la del Señor de Esquipulas, del Día de la Santa Cruz de Roma y la de san Mateo se relacionan en tanto que corresponden al ciclo de la estación lluviosa, teniendo festividades no religiosas de recolección del maíz, y de esa forma compartir con la comunidad las primeras cosechas. El mundo campesino ofrece también elementos culturales que evidencian cómo la tradición se ha mantenido, pero que poco a poco va desconociéndose su posible origen, pues este ha sido modificado con el paso del tiempo, aspectos del mundo cristiano y de la cosmovisión prehispánica con el que conviven a diario; en ese espacio donde la tierra, el agua, la lluvia y la milpa juegan un papel determinante en su cultura campesina, que tuvo un origen en la cultura pipil. 
En relación con la medicina tradicional, el papel de las parteras y los curanderos es, y fue, muy importante hoy en día para la comunidad, en cuanto a que son personas de confianza y son la alternativa a problemas de la salud. Por esta razón, diferentes grupos sociales tienen sus propias formas de concebir a la salud-enfermedad-curación, sobre todo si tienen poco acceso a clínicas u hospitales; eso implica que desarrollen sus propias prácticas de medicina tradicional. Comprender estas acciones lleva a cuestionarse cómo la cultura y la tradición han jugado un papel importante en la transmisión de saberes ancestrales. Aún queda mucho camino por recorrer. Si la política nacional de salud para pueblos indígenas abre un espacio para el debate y a la posible incorporación de las parteras y curanderos en este sistema de salud intercultural, mucho se habrá ganado. En la medida en que se formen futuros especialistas en salud tradicional, podría garantizarse menos casos lamentables en mujeres embarazadas y sus hijos.

Se observa la pertenencia étnica de los comayagüenses a un pasado común, a un pasado indígena, que se torna en una característica importante de su comunidad y que se presta desde diversas caras, según la situación en la que se encuentre, como una manera de protección y de resistencia ante los agentes externos. En estas comunidades rurales de Comasagua se encuentran individuos o grupos que poseen un fundamento ancestral en creencias y prácticas espirituales; también guardan y fomentan los rituales concernientes a los ciclos de la vida productivos y de la naturaleza, así como utilizan la medicina ancestral, la visión del mundo mitológico, el calendario agrícola y religioso, entre otros elementos del perfil de los pueblos indígenas de El Salvador.

\section{Referencias}

Aigneren, M. (2002). "La técnica de recolección de información mediante los grupos focales". En: Revista electrónica La Sociología en sus Escenarios, No. 6, pp. 1-32. Colombia: Universidad de Antioquia, Centro de Estudios de Opinión.

Castillo, B. (2012). "Medicina tradicional entre los indígenas de Izalco, Sonsonate, El Salvador". San Salvador: Tecnoimpresos.

Diario Oficial, Tomo 395, San Salvador, miércoles 25 de abril de 2012. Número 75.

Digestyc (2008). "VI Censo de Población y V de Vivienda 2007". Ministerio de Economía, Dirección General de Estadística y Censos. San Salvador, El Salvador.

Erquicia, J.; M. Herrera y A. Pleitez (2014). "Historia, patrimonio e identidades en la villa de Huizúcar, La Libertad, El Salvador". Colección Investigaciones; v. 31. Universidad Tecnológica de El Salvador (Utec).

Escamilla, M. (2007). “El Salvador rupestre: Reconocimiento y registro de sitios". En: "XX Simposio de Investigaciones Arqueológicas en Guatemala, 2006" (editado por J.P. Laporte, B. Arroyo y H. Mejía), pp. 1219-1233. Museo Nacional de Arqueología y Etnología, Guatemala.

Ghidinelli, A. (1984). “El sistema de ideas sobre la enfermedad en Mesoamérica". En: Revista Médica Hondureña. No. 4. Vol. 52, pp. 237-248.

Marroquín, A. (1975). "El problema indígena en El Salvador". En: Instituto Indigenista Americano. Revista América Indígena, Volumen XXXV, No. 4, Octubre-Diciembre, 1975. México.

Vela Peón, F. (2001). "Un acto metodológico básico de la investigación social: la entrevista cualitativa". En: María Luisa Tarrés, "Observar, escuchar y comprender sobre la tradición cualitativa en la investigación social". Flacso y El Colegio de México, México, 2001.

Velásquez, J. (1996). La partera salvadoreña. El Salvador: Editorial Universitaria. 